\title{
$G$ protein-coupled receptors function as cell membrane receptors for the steroid hormone 20-hydroxyecdysone
}

\author{
Xiao-Fan Zhao@
}

\begin{abstract}
G protein-coupled receptors (GPCRs) are cell membrane receptors for various ligands. Recent studies have suggested that GPCRs transmit animal steroid hormone signals. Certain GPCRs have been shown to bind steroid hormones, for example, G protein-coupled estrogen receptor 1 (GPER1) binds estrogen in humans, and Drosophila dopamine/ecdysteroid receptor (DopEcR) binds the molting hormone 20-hydroxyecdysone (20E) in insects. This review summarizes the research progress on GPCRs as animal steroid hormone cell membrane receptors, including the nuclear and cell membrane receptors of steroid hormones in mammals and insects, the 20E signaling cascade via GPCRs, termination of 20E signaling, and the relationship between genomic action and the nongenomic action of 20E. Studies indicate that 20E induces a signal via GPCRs to regulate rapid cellular responses, including rapid $\mathrm{Ca}^{2+}$ release from the endoplasmic reticulum and influx from the extracellular medium, as well as rapid protein phosphorylation and subcellular translocation. 20E via the GPCR/Ca ${ }^{2+} / \mathrm{PKC} /$ signaling axis and the GPCR/CAMP/PKAsignaling axis regulates gene transcription by adjusting transcription complex formation and DNA binding activity. GPCRs can bind 20E in the cell membrane and after being isolated, suggesting GPCRs as cell membrane receptors of 20E. This review deepens our understanding of GPCRs as steroid hormone cell membrane receptors and the GPCR-mediated signaling pathway of 20E (20E-GPCR pathway), which will promote further study of steroid hormone signaling via GPCRs, and presents GPCRs as targets to explore new pharmaceutical materials to treat steroid hormone-related diseases or control pest insects.
\end{abstract}

Keywords: GPCR, Steroid hormone, 20-hydroxyecdysone, Cell membrane receptor, Signal pathway

\section{Background}

G protein-coupled receptors (GPCRs) are seventransmembrane proteins that are located in the cell membrane, with their $\mathrm{N}$ - and $\mathrm{C}$-termini located on the outer and inner surfaces, respectively. GPCRs mediate various cellular responses from the extracellular environment. A GPCR is activated upon binding of its ligand, which causes a conformational change in the GPCR's structure. The activated GPCR then interacts with G

\section{Correspondence: xfzhao@sdu.edu.cn}

Shandong Provincial Key Laboratory of Animal Cells and Developmental Biology, School of Life Sciences, Shandong University, Qingdao 266237, China

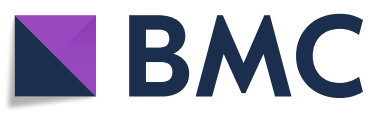

protein to induce further signaling cascades [1]. Over 800 GPCRs have been identified in the human genome [2], 1000 in the Caenorhabditis elegans genome [3], and 200 in the Drosophila melanogaster genome [4]. GPCRs have been identified as the cell membrane receptors of various ligands, including biological amines, amino acids, ions, lipids, peptides/proteins, light, odorant, pheromones, nucleotides, and opiates [5]. However, the functions and pathways of GPCRs as receptors of animal, including insect steroid hormones have not been fully determined. This present review integrates evidence obtained from insects and mammals to demonstrate that

(c) The Author(s). 2020 Open Access This article is licensed under a Creative Commons Attribution 4.0 International License, which permits use, sharing, adaptation, distribution and reproduction in any medium or format, as long as you give appropriate credit to the original author(s) and the source, provide a link to the Creative Commons licence, and indicate if changes were made. The images or other third party material in this article are included in the article's Creative Commons licence, unless indicated otherwise in a credit line to the material. If material is not included in the article's Creative Commons licence and your intended use is not permitted by statutory regulation or exceeds the permitted use, you will need to obtain permission directly from the copyright holder. To view a copy of this licence, visit http://creativecommons.org/licenses/by/4.0/. The Creative Commons Public Domain Dedication waiver (http://creativecommons.org/publicdomain/zero/1.0/) applies to the data made available in this article, unless otherwise stated in a credit line to the data. 
GPCRs function as cell membrane receptors of animal steroid hormones.

\section{Steroid hormones and their nuclear and cell membrane receptors in mammals}

Steroids are small lipophilic organic molecules with a four-ring structure, which are found in animals, plants, and fungi. The steroid cholesterol is an essential component of animal cell membranes, where it maintains membrane structure and fluidity. Most steroids function as signaling molecules, such as hormones [6]. Animal steroid hormones include estrogens, androgens, glucocorticoids, mineralocorticoids, and progestogens. Steroid hormones play vital roles in various processes in humans and animals. Thus, understanding the signaling pathways of steroid hormones is very important.

Animal steroid hormones are known exert their actions via binding to their intracellular nuclear receptors [7], for example, estrogen binds to its nuclear estrogen receptors ER $\alpha$ and ER $\beta$ [8], androgens bind to androgen receptors (AR) [9], and glucocorticoids bind to glucocorticoid receptors [10]. However, the plant steroid hormones, brassinosteroids, initiate signaling by combining with plasma membrane receptors [11]. The structural similarities between plant steroid hormones and animal steroid hormones [12] have led researchers to investigate the cell membrane receptors for animal steroid hormones.

Extensive evidence indicates that animal steroids activate receptors on the cell membrane. Steroid hormone action in musculoskeletal cells involves membrane receptors and the rapid cellular responses to regulate gene expression via signaling cascades [13]. However, these rapid cellular responses do not rely on gene expression and are therefore designated as nongenomic responses to distinguish them from the genomic responses that are based on gene transcription. For example, estrogen activates phosphoinositide 3 kinase (PI3K) to recruit protein kinase $\mathrm{B}(\mathrm{AKT} / \mathrm{PKB})$ to the cell membrane in mammals via a mechanism independent of the genomic actions of hormones [14]. Pregnenolone, the precursor of androgens, estrogens, progesterone, mineralocorticoids, and glucocorticoids [15], regulates gene expression via a nuclear receptor-mediated genomic pathway and via a transient receptor potential (TRP) cation channelsmediated nongenomic pathway [16]. Several GPCRs are reported as progesterone receptors $(\mathrm{mPR} \alpha, \mathrm{mPR} \beta$, $\mathrm{mPR} \gamma, \mathrm{mPR} \delta$, and $\mathrm{mPR} \varepsilon$ ) [17]. The cell membrane receptors of progestin have been identified in vertebrates $[17,18]$. Androgen transmits signals via cell membrane receptors [19], which are distinct from the androgen nuclear receptors [20]. A zinc influx transporter (ZIP9), which is not a GPCR, has been identified as a membrane androgen receptor [21]. Testosterone mediates nongenomic effects via a calcium and amino acid sensing GPCR (GPRC6A) [22]. The estrogen receptor GPCR (GPR30) [23], which transmits estrogen signals from the membrane [24], has been renamed as $G$ protein-coupled estrogen receptor 1 (GPER1) [25]. Estrogen transmits signals via GPERs to transactivate epidermal growth factor receptors for cell proliferation in female reproductive cancers [26]. GPER1 is reportedly located in the endoplasmic reticulum, but might translocate to the cell membrane [27]. Recent studies have revealed that GPER is constitutively internalized in an arrestin-independent manner and does not recycle to the cell membrane for further signaling [28]. GPER1-mediated nongenomic activity is independent of the estrogen nuclear receptor [26]. In addition to its function in estrogen signaling, GPER1 also functions in other biological systems, such as the nervous system to mediate neuroprotection; therefore, GPER1 is considered to be a pharmacological target $[29,30]$. The identification of GPER1 opens a new field of research [31]. Accumulating evidences supports membrane-initiated estrogen signaling [32]. However, these non-classical steroid actions are not widely accepted and littles progress has been made since the discovery of rapid steroid hormone actions in the 1980s [33]. Identification of the steroid ligands of GPCRs represents a major challenge for studies of the steroid hormone nongenomic pathways [34].

\section{0-hydroxyecdysone and its nuclear and cell membrane receptors in insects}

20-hydroxyecdysone (20E), which is also known as the insect molting hormone, initiates insect larval molting from one instar to the next (molting), or the metamorphic molting from larva to adult (metamorphosis) $[35,36]$. Similar to other animal steroid hormones, 20E is thought to diffuse freely into cells because it is a fatsoluble molecule. 20E binds to its nuclear receptor, ecdysone receptor (EcR), to exert its effect on gene transcription in the classical genomic pathway. EcR must interact with the ultraspiracle protein (USP), retinoid X receptor (RXR) in Hemimetabola, the ortholog of the retinoid $\mathrm{X}$ receptor in vertebrates, to form a heterodimeric transcription complex, EcR/USP [37]. This complex binds to ecdysone response elements (EcRE) to regulate 20E-responsive gene transcription [36], such as hormone receptor 3 (HR3), an early-late gene in the $20 \mathrm{E}$ pathway [38].

The earlier evidence that 20E triggers rapid nongenomic actions before gene transcription was obtained in studies of the anterior silk gland of Bombyx mori. The plasma membrane can bind $\left[{ }^{3} \mathrm{H}\right]$ ponasterone A $\left(\left[{ }^{3} \mathrm{H}\right]\right.$ Pon A), suggesting the existence of an unknown membrane receptor [39]. Other evidence is provided by the 
observation that $20 \mathrm{E}$ induces rapid increase of $\mathrm{Ca}^{2+}$ levels in the cells of the anterior silk gland of B. mori via an unknown GPCR pathway [40]. 20E also triggers rapid increased $\mathrm{Ca}^{2+}$ in mouse skeletal muscle cells via GPCRs [41]. However, the cell membrane receptor-mediated nongenomic pathway of $20 \mathrm{E}$ is not fully understood.

A GPCR, Drosophila melanogaster dopamine/ecdysteroid receptor (DmDopEcR), is considered a 20E cell membrane receptor in Drosophila. The supporting evidence includes the observation that the membrane of Sf9 cells that overexpress DmDopEcR could bind $\left[{ }^{3} \mathrm{H}\right]$ Pon A. In addition, 20E triggers intracellular rapid increases in $\mathrm{Ca}^{2+}$ and cyclic adenosine monophosphate (cAMP), and increases ERK phosphorylation in the DmDopEcR overexpressing Sf9 cells [42]. DmDopEcR functions as a $20 \mathrm{E}$ receptor to modulate the basal and acute physiology of brain structures and behavior [43]. Agrotis ipsilon DopEcR (AipsDopEcR) is predominantly expressed in the nervous system, including the mushroom bodies. AipsDopEcR is involved in the expression of sexual behavior in the male moth [44]. 20E and dopamine (DA), via AipsDopEcR, control sex pheromone perception in the central nervous system [45]. DopEcR plays a significant role in the rapid actions of steroids in a variety of biological processes, such as behavioral modulation in the nervous system [43]. DopEcR plays multiple functions in response to various stressors in Drosophila [46]. The evidence suggests that 20E transmits signals via cell membrane receptors and that a nongenomic pathway exists.

\section{The 20E signaling cascade via GPCRs}

The 20E-responsive GPCR (initially designated ErGPCR, and later, ErGPCR-1) [47] and ErGPCR-2 [48] are further revealed in Helicoverpa armigera. ErGPCR-1 expression levels are increased at the molting and metamorphic stages under 20E regulation. ErGPCR-1 is essential for 20E pathway gene expression and larvalpupal transition. Overexpression of ErGPCR-1 in HaEpi cells ( $H$. armigera epidermal cell line) increases 20E pathway-related gene expression. 20E induces a rapid increase in cytosolic $\mathrm{Ca}^{2+}$ levels and promotes calponin nuclear translocation and phosphorylation via ErGPCR1 [47]. ErGPCR-2 has a similar function to ErGPCR-1, such as regulation of rapid increases in intracellular $\mathrm{Ca}^{2+}$ levels, and phosphorylation of USP [48]. The main difference is that ErGPCR-2 can be internalized from the cell membrane to the cytosol under 20E induction. After internalization, ErGPCR-2 is degraded by proteases to terminate 20E signaling. $\left[{ }^{3} \mathrm{H}\right]$ Pon A entry into cells relies on ErGPCR-2 localization in the cell membrane [48]. A recent study shows that ErGPCR-2 and DopEcR in $H$. armigera could bind $20 \mathrm{E}$ in the cell membrane or as isolated proteins, using a $20 \mathrm{E}$ enzyme immunoassay
(20E-EIA). That study also demonstrates one of the mechanisms by which $20 \mathrm{E}$ represses larval feeding and promotes metamorphosis: 20E competes with dopamine to bind to DopEcR to block the dopamine-mediated motor function and reward-motivated behavior, and initiates the 20E pathway [49].

Both ErGPCR-1 and ErGPCR-2 belong to the Methuselah-2 GPCRs of the class B secretin family and are located in the cell membrane. However, ErGPCR-1 contains 489 amino acids with a 19 -amino acid signal peptide, whereas ErGPCR-2 contains 757 amino acids without a signal peptide [48]. In contrast, $\mathrm{DmDopEcR}$ shows homology with vertebrate ARs in GPCR class A [42]. Phylogenetic analysis using amino acid sequences show that ErGPCR-1 and ErGPCR-2 differ from GPR30, beta-2 AR, or Drosophila DmDopEcR [48]. Studies on ErGPCR-1, ErGPCR-2, and DopEcR suggest the possibility that several GPCRs are involved in 20E signaling via the participation of several downstream cascades or the differential expression and distribution of GPCRs in tissues [49].

G proteins directly transmit GPCR signals [1]. In $H$. armigera, the phosphorylation of $\mathrm{G}$ protein alpha $\mathrm{q}$

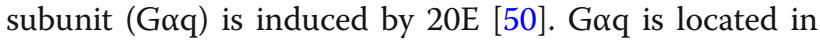
the cytoplasm in HaEpi cells and is induced to migrate toward the cell membrane by 20E. 20E induces Goq protein kinase $\mathrm{C}$ (PKC)-phosphorylation and membrane trafficking. Goq participates in the 20E-induced increase in intracellular $\mathrm{Ca}^{2+}$ levels and is necessary for larval development, metamorphosis, and 20E pathway gene expression, and plays roles downstream of ErGPCR-1 in 20E signaling [50]. Goq directly activates phospholipase $C \beta$ [51]. The mRNA levels of phospholipase $C$ gamma 1 (PLCG1) are increased at the molting and metamorphic stages in $H$. armigera [52]. In that study, RNAimediated silencing of PLCG1 blocks 20E-induced pupation, larval death, and pupation. 20E pathwayrelated gene expression is also repressed by PLCG1 silencing. Studies in $H$. armigera demonstrate that the function of PLCG1 in the 20E signaling pathway is mediated via ErGPCR-1, Goq, and Src-family kinases, and that 20E mediates tyrosine phosphorylation at the $\mathrm{SH} 2$ domain of PLCG1. Activated-PLCG1 migrates toward the cell membrane to initiate intracellular $\mathrm{Ca}^{2+}$ signaling and calcium channel-controlled $\mathrm{Ca}^{2+}$ influx, which triggers $\mathrm{PKC}$-mediated USP phosphorylation to modulate USP binding to EcRE for subsequent gene transcription. These findings provide evidence that $20 \mathrm{E}$ regulates the genomic pathway for gene transcription through an ErGPCR-1/ Goq/PLCG1/Ca ${ }^{2+}$ PKCdependent nongenomic pathway [52].

$\mathrm{Ca}^{2+}$ ion is an important secondary signal messenger in cells. The concentration of $\mathrm{Ca}^{2+}$ is well controlled at low levels inside cells, but can be increased by influx from outside the cells by various signals [53]. After 
signaling, the intracellular $\mathrm{Ca}^{2+}$ is decreased by excluding $\mathrm{Ca}^{2+}$ out of cells and storing $\mathrm{Ca}^{2+}$ in the endoplasmic reticulum (ER) [54]. 20E induces a rapid increase in the intracellular $\mathrm{Ca}^{2+}$ levels [40]; however, the mechanism and consequences were not revealed until recent studies in $H$. armigera. $\mathrm{Ca}^{2+} /$ calmodulin-dependent protein kinase II (CaMKII) is a serine/threonine-specific protein kinase that is regulated by the $\mathrm{Ca}^{2+} /$ calmodulin complex [55]. CaMKII expression and phosphorylation increase during metamorphosis in H. armigera [56]. 20E regulates phosphorylation of CaMKII at threonine 290, which induces CaMKII translocation into the nucleus. ErGPCR-1 and ErGPCR-2, Goq, PLC, and $\mathrm{Ca}^{2+}$-signaling are involved in 20E-induced CaMKII phosphorylation. RNAi-mediated CaMKII knockdown prevents larval-pupal transition and 20E-responsive gene expression. The phosphorylation and nuclear translocation of CaMKII induces the phosphorylation and nuclear export of histone deacetylase 3, thus maintaining USP lysine acetylation at amino acid 303. This modification is necessary for its interaction with EcR to form the transcription complex and for the binding of the EcR-USP complex to EcRE [56]. 20E, through GPCRs, induces intracellular $\mathrm{Ca}^{2+}$ release, which causes stromal interaction molecule 1 (STIM1) phosphorylation and aggregation. Aggregated-STIM1 moves toward the plasma membrane to interact with orail for $\mathrm{Ca}^{2+}$ entry [57]. In turn, orail expression is upregulated by $20 \mathrm{E}$ [58]. The high levels of 20E switches autophagy to apoptosis in the $H$. armigera midgut by increasing the $\mathrm{Ca}^{2+}$ levels in cells [59], thereby inducing apoptosis [60]. Therefore, 20E increases the intracellular $\mathrm{Ca}^{2+}$ levels via a store-operated $\mathrm{Ca}^{2+}$ entry (SOCE) mechanism.

In addition to triggering rapid increases in intracellular $\mathrm{Ca}^{2+}$ levels to activate the PKC pathway, 20E also stimulates a rapid increase in cAMP levels and activates the protein kinase A (PKA) pathway in H. armigera [61]. The expression of the catalytic subunit 1 of PKA (PKAC1) increases during metamorphosis, and that PKAC1 knockdown blocks pupation and represses 20E-responsive gene expression. Through ErGPCR2, 20E regulates PKAC1 phosphorylation and its nuclear translocation. PKAC1 induces the phosphorylation of cAMP response elementbinding protein (CREB) at serine 143, which allows it to bind to the cAMP response element (CRE) to enhance 20E-responsive gene transcription. Through ErGPCR2, 20E increases cellular cAMP levels, which induces PKAmediated CREB -phosphorylation and, in turn, promotes 20E-responsive gene expression. Thus, the 20E-induced PKA/CREB pathway enhances the 20E-induced PKC pathway for gene transcription [61].

\section{Termination of $20 \mathrm{E}$ signaling}

The mechanism by which the 20E signal is desensitized remains unclear. A study in $H$. armigera showed that $\beta$ - arrestin-1 expression levels are markedly increased in tissues during $H$. armigera metamorphosis [62]. Further study showed that in contrast to the 20E-promoted pupation, interference with Arrb1 (encoding $\beta$-arrestin-1) by dsRNA injection into larvae causes advanced pupation and a chimeric larva-pupa phenotype. $\beta$-arrestin- 1 depletion increases the mRNA levels of 20E-responsive genes, while their levels are decreased by Arrb1 mRNA overexpression. Following 20E induction, $\beta$-arrestin- 1 migrates to the cytoplasmic membrane from the cytoplasm to interact with ErGPCR-1. Via ErGPCR1, 20E regulates $\beta$ arrestin-1 phosphorylation at serines 170 and 234, and mutation of these residues inhibits 20E-induced $\beta$ arrestin-1 migration to the cell membrane. Therefore, via negative feedback mechanism, 20E induces $\beta$-arrestin-1 phosphorylation and cell membrane migration, which blocks 20E signaling by the interaction between $\beta$ arrestin-1 and ErGPCR-1 [62].

GPCR kinase (GRK)-induced desensitization of 20Emediated GPCR signaling in the cell membrane was first revealed in $H$. armigera [63]. GRK2 protein levels increase during the metamorphic stage under $20 \mathrm{E}$ regulation. GRK2 knockdown in larvae causes accelerated pupation, an increase in 20E-responsive gene expression, and advanced apoptosis and metamorphosis. 20E induces GRK2 translocation from the cytosol to the cell membrane via 20E-responsive ErGPCR-2. GRK2 is phosphorylated at serine 680 by PKC after induction by $20 \mathrm{E}$, which leads to the translocation of GRK2 to the cell membrane. GRK2 then interacts with ErGPCR-2 and phosphorylates ErGPCR-2 to induce its internalization. Therefore, GRK2 terminates the ErGPCR-2 function in 20E signaling at the cell membrane via a negative feedback mechanism [63].

\section{The relationship between genomic actions and the nongenomic actions of steroid hormone}

The genomic actions of a steroid hormone include that the hormone freely diffuses into cells, binds to its nuclear receptor to form transcription complex, and binds to promoter in DNA to initiate gene transcription. This gene transcription-related pathway is named genomic pathway. The genomic action/pathway occurs in the nuclei after the steroid hormone binding to the nuclear receptor; therefore, this pathway is also known as a nuclear receptor pathway. The genomic actions are relatively slow because the gene transcription and protein translation take time. Whereas, the nongenomic actions of a steroid hormone include the rapid cellular responses, such as calcium influx in seconds, variation of protein phosphorylation, subcellular localization and protein interaction. This rapid cellular response-related pathway is named nongenomic pathway. The nongenomic action/pathway occurs in the cytosol after the steroid hormone binding to the cell membrane receptor; 
therefore, this pathway is also known as a cell membrane receptor pathway. An intriguing question is the relationship between the genomic action/pathway and the nongenomic action/pathway. From the studies in $H$. armigera, the genomic action/pathway of $20 \mathrm{E}$ is regulated by the nongenomic action/pathway, because the 20E-induced rapid calcium increase in cells activates protein kinases [52, 56], therefore promotes EcR-USP transcription complex formation, which initiates gene transcription in 20E pathway finally [64]. Therefore, the $20 \mathrm{E}$ signaling pathway is a GPCR-mediated signaling pathway (20E-GPCR pathway).

Another interesting question is whether steroid hormones passively enter cells. An ATP-binding cassette $(\mathrm{ABC})$ protein in the plasma membrane that exports steroids in yeast suggests that similar membrane sorting systems in mammalian cells [65]. In Drosophila, ecdysone is released out of cells via $A B C$ protein that functions as an ecdysone transporter [66, 67]. ErGPCR-2 in the lepidopteran $H$. armigera increases $20 \mathrm{E}$ entering cells [48]. Recent work suggests that $20 \mathrm{E}$ entry into cells is controlled by a 12 transmembrane protein, Ecdysone Importer (EcI), in Drosophila [67]. These data suggest that $20 \mathrm{E}$ is not passively enter the cell membrane [68]. The recent work in $H$. armigera shows the $20 \mathrm{E}$ concentrations are different in various tissues when they are soaked in same hemolymphic 20E concentration [69], suggesting that the different concentrations of $20 \mathrm{E}$ in cells induce different gene transcription via EcR, and $20 \mathrm{E}$ entry into cells is controlled by some unknown mechanism, which needs further study.

\section{Function of ecdysone}

Ecdysone (E) is the precursor of 20E [70]. Insects do not synthesize steroid precursors, but ingest animal cholesterol or plant phytosterols in the form of food, which is then processed to generate ecdysone. 20E is an ecdysteroid hydroxylated at the 20th carbon in addition to other carbons [71]. Although 20E is the active molting hormone and ecdysone is relatively inactive, $\mathrm{E}$ accelerates the metamorphic timing and results in elevation of lethality during metamorphosis in D. melanogaster, suggesting both $20 \mathrm{E}$ and $\mathrm{E}$ are essential for the regulation of metamorphic timing in D. melanogaster [72]. Both E and 20E exist in plants to play roles in the plants or participate in the defense of plants against insects [73]. Therefore, the insecticidal activity of the 20E can be developed to control insect pests [74].

\section{Discussion}

GPR30 is suggested as the cell membrane receptor for the steroid hormone estrogen by detection of the binding of fluorescence-labeled estrogen in Cos7 cells [25]. Subtypes of estrogen receptors of GPER are found in human cerebral vascular endothelial cells [75]. DmDopEcR in Drosophila is reported to bind the 20E analog $\left[{ }^{3} \mathrm{H}\right]$-labeled Pon A [30]. DopEcR in $H$. armigera can bind $20 \mathrm{E}$ in the cell membrane or as an isolated protein [49]. To prove the GPCRs binding steroid hormone is very difficult. One reason is the difficulty of overexpressing and purifying GPCRs. Another reason is the difficulty of labeling the ligands and detecting ligand binding to the dynamic GPCR proteins [76]. GPCRs undergo highly dynamic structural changes during signal transduction upon the binding of their ligands and interactions with intracellular effectors [77]. For example, ligand binding to beta-adrenergic receptors (ARs) results in a conformational change that activates Gs protein complexes [78]. The cholesterol binding site on the lipid-transmembrane interface of 2-AR has been reproduced in different crystal forms [79]. The cholesterol hot-spots of GPCRs have a microsecond time scale of exchange upon lipid binding; therefore, they might be termed "high occupancy sites" rather than "binding sites" [80]. Therefore, investigation of individual GPCRs using conventional experimental techniques is extremely challenging [81]. A suitable method to detect the dynamic binding of small lipid ligands to GPCRs needs to be established. 20E-EIA detects the binding of GPCRs to $20 \mathrm{E}$ directly, presenting an alternative method to that using the isotope-labeled analog Pon A [49].

GPCRs are considered to function not as a single molecule, but in the form of homo- or hetero-oligomers [82]. Some GPCRs can form receptor mosaics via the further assembly of three or more protomers [83]. Oligomerization of GPCRs results in the diversification of receptor signaling [84]. GPCRs exist as an ensemble of temporally interchanging conformations [85]. Although the significance of homo- or hetero-oligomers of GPCRs is unclear, the study of GPCR oligomers might reveal evidence to explain the reported involvement of various GPCRs in the same signal pathways.

20E regulates gene transcription via its nuclear receptor EcR in $H$. armigera [64]. Via the GPCR-mediated nongenomic pathway, 20E regulates the phosphorylation and lysine acetylation of nuclear transcription factors to form the transcription complex, EcR/USP, and the binding to EcRE for further gene transcription; therefore, via the nongenomic pathway, 20E regulates the genomic pathway. 20E signaling might involve several GPCRs, probably depending on GPCR homo- or heterooligomerization, their tissue specific distribution, timerelated expression patterns, and downstream factors, all of which require further investigation.

20E, which is produced in both insects and plants, such as Cyanotis vaga, can be used to disrupt the development of insect pests [86]. Insect ecdysone is converted from dietary cholesterol in the insect prothoracic gland and 
then processed into $20 \mathrm{E}$ in the hemolymph or tissues [87]. $20 \mathrm{E}$ can be used as a food additive to help maintain the glucose-lipid balance in humans, without the side effects associated with the use of mammalian hormones [88]. 20E changes energy metabolism to inhibit stem cell proliferation in Drosophila [89]. In H. armigera, high concentrations of 20E induce $\mathrm{Ca}^{2+}$ influx to switch autophagy to apoptosis in the midgut $[59,60]$. The identification of GPCRs as 20E cell membrane receptors will improve our understanding of the roles of $20 \mathrm{E}$ and its mechanism of action in mammals and in insects.

Approximately $30-35 \%$ of marketed drug targets are GPCRs [90-92]. The challenge to achieving full elucidation of the steroid hormone-GPCR pathway is critically dependent on establishing a method to detect the highly dynamic conformations of GPCRs and their interaction with steroids. Recent researches in insects have revealed the axis of the 20E signaling pathway via GPCRs, which will encourage the study of steroid hormone signaling pathways that act via GPCRs. In addition, GPCRs represent targets to develop new types of insecticides.

\section{Conclusions}

Studies of the insect steroid hormone 20E show that GPCRs function as cell membrane receptors of steroid hormones. 20E binds to GPCRs to trigger the PKA and PKC pathways via Gos and Goq, respectively. 20E induces calcium influx by SOCE via Gaq, PLC, STIM, and Orai-signaling. The increased level of calcium acts as a secondary messenger to induce protein phosphorylation and acetylation to regulate the nuclear receptor transcriptional complex formation for gene transcription and apoptosis. 20E, via the PKA pathway, enhances the PKC pathway. 20E signaling is terminated by desensitization of GPCRs via a negative feedback mechanism. A GPCR-mediated signaling pathway of $20 \mathrm{E}$ (20E-GPCR pathway) has been elucidated, which opens a door to further study of steroid hormone signaling via GPCRs (Fig. 1). There are still many questions need to be answered, such as the facilitated- or passive-entry of steroid hormones into cells, the homo- or heterooligomerization of GPCRs, and several GPCRs function in a same pathway.

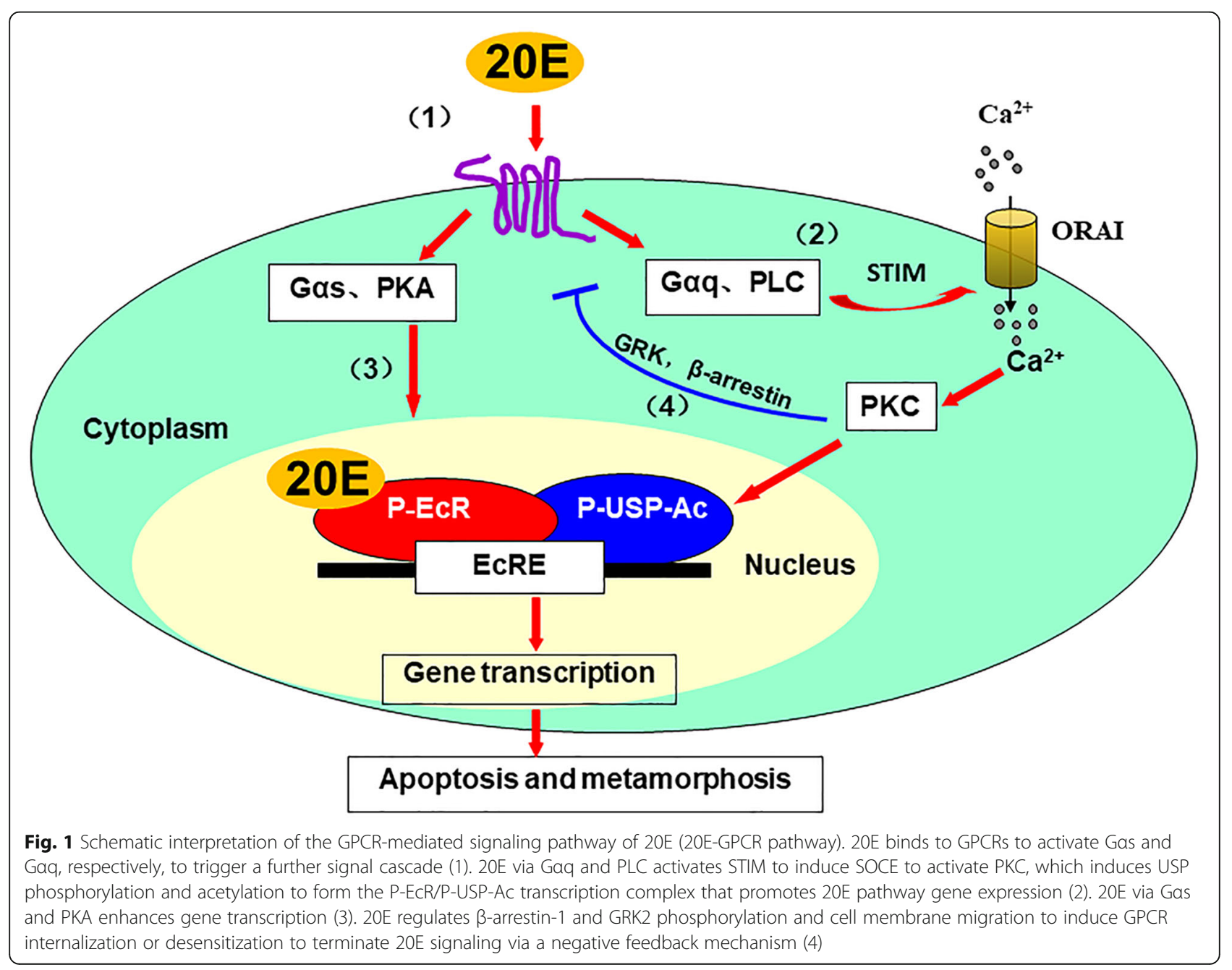




\section{Abbreviations}

GPCR: G protein-coupled receptors; GPER1: G protein-coupled estrogen receptor 1; DopEcR: Dopamine/ecdysteroid receptor; 20E: 20-hydroxyecdysone; EcR: Ecdysone receptor; USP/RXR: Ultraspiracle protein/retinoid X receptor; ErGPCR: 20E-responsive GPCR; ER: Estrogen receptors; AR: Androgen receptors; PLC: Phospholipase C; STIM1: Stromal interaction molecule 1; SOCE: Store-operated $\mathrm{Ca}^{2+}$ entry; PKA: Protein kinase A; PKC: Protein kinase C; Gaq: G protein alpha q subunit; CAMP: Cyclic adenosine monophosphate; $\left.{ }^{3} \mathrm{H}\right]$ Pon A: $\left.{ }^{3} \mathrm{H}\right]$ ponasterone A; GRK: GPCR kinase; CREB: camp response element-binding protein; HaEpi cells: H. armigera epidermal cell line

\section{Acknowledgments}

Not applicable.

\section{Author's contributions}

XFZ wrote the manuscript. The author read and approved the final manuscript.

\section{Funding}

This study was supported by grants from the National Natural Science Foundation of China (31730083 and 31572328). The funding body did not play roles in the design of the study and collection, analysis, and interpretation of data and in writing.

\section{Availability of data and materials Not applicable.}

\section{Ethics approval and consent to participate}

Not applicable.

\section{Consent for publication}

Not applicable.

\section{Competing interests}

The authors declare that they have no competing interests.

Received: 22 February 2020 Accepted: 27 June 2020

Published online: 09 September 2020

\section{References}

1. Preininger AM, Meiler J, Hamm HE. Conformational flexibility and structural dynamics in GPCR-mediated G protein activation: a perspective. J Mol Biol (4517). 2013;425:2288-98.

2. Lin HH, Stacey M. G protein-coupled receptors in macrophages. Microbiol Spectr. 2016;4:1

3. Bargmann $\mathrm{Cl}$. Neurobiology of the Caenorhabditis elegans genome. Science (34661). 1998;282:2028-33.

4. Adams MD, Celniker SE, Holt RA, Evans CA, Gocayne JD, Amanatides PG, et al. The genome sequence of Drosophila melanogaster. Science (34661). 2000:287:2185-95.

5. Marinissen MJ, Gutkind JS. G-protein-coupled receptors and signaling networks: emerging paradigms. Trends Pharmacol Sci (1184). 2001;22:368-76.

6. Moss GP. The nomenclature of steroids - recommendations 1989. Eur J Biochem. 1989;186:429-58.

7. Weigel NL, Moore NL. Kinases and protein phosphorylation as regulators of steroid hormone action. Nucl Recept Signal. 2007:5:e005.

8. Dahlman-Wright K, Cavailles V, Fuqua SA, Jordan VC, Katzenellenbogen JA Korach KS, et al. International union of pharmacology. LXIV. Estrogen receptors. Pharmacol Rev (18393). 2006:58:773-81.

9. Aarnisalo P, Palvimo JJ, Janne OA. CREB-binding protein in androgen receptor-mediated signaling. Proc Natl Acad Sci U S A. 1998;95:2122-7.

10. Ratman D, Vanden Berghe W, Dejager L, Libert C, Tavernier J, Beck IM, et al. How glucocorticoid receptors modulate the activity of other transcription factors: a scope beyond tethering. Mol Cell Endocrinol (3859). 2013;380:41-54.

11. Bishop GJ, Koncz C. Brassinosteroids and plant steroid hormone signaling. Plant Cell. 2002;14:S97-110

12. Mussig C, Altmann T. Brassinosteroid signaling in plants. Trends Endocrino Metab. 2001;12:398-402.

13. Boyan BD, Dean DD, Sylvia $V L$, Schwartz Z. Steroid hormone action in musculoskeletal cells involves membrane receptor and nuclear receptor mechanisms. Connect Tissue Res. 2003;44(Suppl 1):130-5.
14. Aronica SM, Kraus WL, Katzenellenbogen BS. Estrogen action via the CAMP signaling pathway: stimulation of adenylate cyclase and CAMP-regulated gene transcription. Proc Natl Acad Sci U S A. 1994;91:8517-21.

15. Nilius B, Voets T. A TRP channel-steroid marriage. Nat Cell Biol. 2008;10: 1383-4.

16. Aquila S, Sisci D, Gentile M, Middea E, Catalano S, Carpino A, et al. Estrogen receptor (ER) alpha and ER beta are both expressed in human ejaculated spermatozoa: evidence of their direct interaction with phosphatidylinositol3-OH kinase/Akt pathway. J Clin Endocrinol Metab. 2004;89:1443-51.

17. Kasubuchi M, Watanabe K, Hirano K, Inoue D, Li X, Terasawa K, et al. Membrane progesterone receptor beta (mPRbeta/Paqr8) promotes progesterone-dependent neurite outgrowth in PC12 neuronal cells via nonG protein-coupled receptor (GPCR) signaling. Sci Rep. 2017;7:5168.

18. Zhu Y, Bond J, Thomas P. Identification, classification, and partial characterization of genes in humans and other vertebrates homologous to a fish membrane progestin receptor. Proc Natl Acad Sci U S A. 2003;100:2237-42.

19. Michels G, Hoppe UC. Rapid actions of androgens. Front Neuroendocrinol. 2008;29:182-98.

20. Bennett NC, Gardiner RA, Hooper JD, Johnson DW, Gobe GC. Molecular cell biology of androgen receptor signalling. Int J Biochem Cell Biol. 2010;42: 813-27.

21. Berg AH, Rice CD, Rahman MS, Dong J, Thomas P. Identification and characterization of membrane androgen receptors in the ZIP9 zinc transporter subfamily: I. discovery in female Atlantic croaker and evidence ZIP9 mediates testosterone-induced apoptosis of ovarian follicle cells. Endocrinology. 2014;155:4237-49.

22. Pi M, Parrill AL, Quarles LD. GPRC6A mediates the non-genomic effects of steroids. J Biol Chem. 2010:285:39953-64

23. Revankar CM, Cimino DF, Sklar LA, Arterburn JB, Prossnitz ER. A transmembrane intracellular estrogen receptor mediates rapid cell signaling. Science. 2005;307:1625-30

24. Prossnitz ER, Maggiolini M. Mechanisms of estrogen signaling and gene expression via GPR30. Mol Cell Endocrinol. 2009;308:32-8

25. Maggiolini M, Picard D. The unfolding stories of GPR30, a new membranebound estrogen receptor. J Endocrinol. 2010;204:105-14.

26. Filardo EJ, Thomas P. Minireview: G protein-coupled estrogen receptor-1, GPER-1: its mechanism of action and role in female reproductive cancer renal and vascular physiology. Endocrinology (4159). 2012:153:2953-62.

27. Sanden C, Broselid S, Cornmark L, Andersson K, Daszkiewicz-Nilsson J, Martensson UE, et al. G protein-coupled estrogen receptor $1 / \mathrm{G}$ proteincoupled receptor 30 localizes in the plasma membrane and traffics intracellularly on cytokeratin intermediate filaments. Mol Pharmacol. 2011; 79:400-10.

28. Cheng SB, Quinn JA, Graeber CT, Filardo EJ. Down-modulation of the Gprotein-coupled estrogen receptor, GPER, from the cell surface occurs via a trans-Golgi-proteasome pathway. J Biol Chem (4258). 2011;286:22441-55.

29. Feldman RD, Limbird LE. GPER (GPR30): a nongenomic receptor (GPCR) for steroid hormones with implications for cardiovascular disease and cancer. Annu Rev Pharmacol Toxicol. 2017:57:567-84.

30. Srivastava DP, Evans PD. G-protein oestrogen receptor 1: trials and tribulations of a membrane oestrogen receptor. J Neuroendocrinol (3172). 2013;25:1219-30.

31. Barton M, Filardo EJ, Lolait SJ, Thomas P, Maggiolini M, Prossnitz ER. Twenty years of the $G$ protein-coupled estrogen receptor GPER: historical and personal perspectives. J Steroid Biochem Mol Biol. 2018;176:4-15.

32. Vail G, Roepke TA. Membrane-initiated estrogen signaling via Gq-coupled GPCR in the central nervous system. Steroids. 2019:142:77-83.

33. Thomas P. Rapid steroid hormone actions initiated at the cell surface and the receptors that mediate them with an emphasis on recent progress in fish models. Gen Comp Endocrinol. 2012;175:367-83.

34. Norman AW, Mizwicki MT, Norman DP. Steroid-hormone rapid actions, membrane receptors and a conformational ensemble model. Nat Rev Drug Discov. 2004:3:27-41.

35. Gilbert LI, Granger NA, Roe RM. The juvenile hormones: historical facts and speculations on future research directions. Insect Biochem Mol Biol. 2000;30: 617-44.

36. Riddiford LM, Hiruma K, Zhou X, Nelson CA. Insights into the molecular basis of the hormonal control of molting and metamorphosis from Manduca sexta and Drosophila melanogaster. Insect Biochem Mol Biol. 2003; 33:1327-38. 
37. Oro AE, McKeown M, Evans RM. Relationship between the product of the Drosophila ultraspiracle locus and the vertebrate retinoid $X$ receptor. Nature (38138). 1990;347:298-301.

38. Liu W, Cai MJ, Wang JX, Zhao XF. In a nongenomic action, steroid hormone 20-hydroxyecdysone induces phosphorylation of cyclin-dependent kinase 10 to promote gene transcription. Endocrinology (4159). 2014;155:1738-50.

39. Elmogy M, Iwami M, Sakurai S. Presence of membrane ecdysone receptor in the anterior silk gland of the silkworm Bombyx mori. Eur J Biochem. 2004; 271:3171-9.

40. Manaboon M, Iga M, Iwami M, Sakurai S. Intracellular mobilization of $\mathrm{Ca}^{2+}$ by the insect steroid hormone 20-hydroxyecdysone during programmed cell death in silkworm anterior silk glands. J Insect Physiol. 2009;55:122-8.

41. Gorelick-Feldman J, Cohick W, Raskin I. Ecdysteroids elicit a rapid $\mathrm{Ca}^{2+}$ flux leading to Akt activation and increased protein synthesis in skeletal muscle cells. Steroids (2513). 2010;75:632-7.

42. Srivastava DP, Yu EJ, Kennedy K, Chatwin H, Reale V, Hamon M, et al. Rapid, nongenomic responses to ecdysteroids and catecholamines mediated by a novel Drosophila G-protein-coupled receptor. J Neurosci. 2005;25:6145-55.

43. Lark A, Kitamoto T, Martin JR. Modulation of neuronal activity in the Drosophila mushroom body by DopEcR, a unique dual receptor for ecdysone and dopamine. Biochim Biophys Acta, Mol Cell Res. 1864;2017: 1578-88.

44. Abrieux A, Debernard S, Maria A, Gaertner C, Anton S, Gadenne C, et al. Involvement of the G-protein-coupled dopamine/ecdysteroid receptor DopEcR in the behavioral response to sex pheromone in an insect. PLoS One. 2013;8:e72785.

45. Abrieux A, Duportets L, Debernard S, Gadenne C, Anton S. The GPCR membrane receptor, DopEcR, mediates the actions of both dopamine and ecdysone to control sex pheromone perception in an insect. Front Behav Neurosci. 2014:8:312

46. Petruccelli E, Lark A, Mrkvicka JA, Kitamoto T. Significance of DopEcR, a Gprotein coupled dopamine/ecdysteroid receptor, in physiological and behavioral response to stressors. J Neurogenet. 2020;1:1-14.

47. Cai MJ, Dong DJ, Wang Y, Liu PC, Liu W, Wang JX, et al. G-protein-coupled receptor participates in 20-hydroxyecdysone signaling on the plasma membrane. Cell Commun Signal (3661). 2014;12:9.

48. Wang D, Zhao WL, Cai MJ, Wang JX, Zhao XF. G-protein-coupled receptor controls steroid hormone signaling in cell membrane. Sci Rep. 2015;5:8675.

49. Kang XL, Zhang JY, Wang D, Zhao YM, Han XL, Wang JX, et al. The steroid hormone 20-hydroxyecdysone binds to dopamine receptor to repress lepidopteran insect feeding and promote pupation. PLoS Genet. 2019;15: e1008331.

50. Ren J, Li XR, Liu PC, Cai MJ, Liu W, Wang JX, et al. G-protein alphaq participates in the steroid hormone 20-hydroxyecdysone nongenomic signal transduction. J Steroid Biochem Mol Biol. 2014;144:313-23.

51. Taylor SJ, Chae HZ, Rhee SG, Exton JH. Activation of the beta 1 isozyme of phospholipase $\mathrm{C}$ by alpha subunits of the $\mathrm{Gq}$ class of $\mathrm{G}$ proteins. Nature (38138). 1991;350:516-8.

52. Liu W, Cai MJ, Zheng CC, Wang JX, Zhao XF. Phospholipase C gamma 1 connects the cell membrane pathway to the nuclear receptor pathway in insect steroid hormone signaling. J Biol Chem. 2014;289:13026-41.

53. Clapham DE. Calcium signaling. Cell. 2007;131:1047-58.

54. Clapham DE. Calcium signaling. Cell. 1995;80:259-68.

55. Erickson JR. Mechanisms of CaMKII activation in the heart. Front Pharmacol (4418). 2014:5:59

56. Jing YP, Liu W, Wang JX, Zhao XF. The steroid hormone 20hydroxyecdysone via nongenomic pathway activates Ca2+/calmodulindependent protein kinase II to regulate gene expression. J Biol Chem. 2015; 290:8469-81.

57. Chen CH, Di YQ, Shen QY, Wang JX, Zhao XF. The steroid hormone 20hydroxyecdysone induces phosphorylation and aggregation of stromal interacting molecule 1 for store-operated calcium entry. J Biol Chem. 2019; 294:14922-36

58. Li YB, Pei XY, Wang D, Chen CH, Cai MJ, Wang JX, et al. The steroid hormone 20-hydroxyecdysone upregulates calcium release-activated calcium channel modulator 1 expression to induce apoptosis in the midgut of Helicoverpa armigera. Cell Calcium. 2017;68:24-33.

59. Li YB, Li XR, Yang T, Wang JX, Zhao XF. The steroid hormone 20hydroxyecdysone promotes switching from autophagy to apoptosis by increasing intracellular calcium levels. Insect Biochem Mol Biol. 2016;79: 73-86.
60. Wang D, Pei XY, Zhao WL, Zhao XF. Steroid hormone 20-hydroxyecdysone promotes higher calcium mobilization to induce apoptosis. Cell Calcium. 2016;60:1-12.

61. Jing YP, Wang D, Han XL, Dong DJ, Wang JX, Zhao XF. The steroid hormone 20-hydroxyecdysone enhances gene transcription through the CAMP response element-binding protein (CREB) signaling pathway. J Biol Chem. 2016;291:12771-85

62. Zhang XQ, Li XR, Ren J, Li YB, Cai MJ, Wang JX. Zhao XF: beta-Arrestin1 interacts with $\mathrm{G}$ protein-coupled receptor to desensitize signaling of the steroid hormone 20-hydroxyecdysone in the lepidopteran insect Helicoverpa armigera. Cell Signal. 2015;27:878-86.

63. Zhao WL, Wang D, Liu CY, Zhao XF. G-protein-coupled receptor kinase 2 terminates $\mathrm{G}$-protein-coupled receptor function in steroid hormone 20hydroxyecdysone signaling. Sci Rep. 2016;6:29205.

64. Chen CH, Pan J, Di YQ, Liu W, Hou L, Wang JX, et al. Protein kinase C delta phosphorylates ecdysone receptor B1 to promote gene expression and apoptosis under 20-hydroxyecdysone regulation. Proc Natl Acad Sci U S A. 2017;114:E7121-30.

65. Thompson EB. Steroid hormones. Membrane transporters of steroid hormones. Curr Biol (8983). 1995;5:730-2.

66. Yamanaka N, Marques G, O'Connor MB. Vesicle-mediated steroid hormone secretion in Drosophila melanogaster. Cell. 2015;163:907-19.

67. Okamoto N, Viswanatha R, Bittar R, Li Z, Haga-Yamanaka S, Perrimon N, et al. A membrane transporter is required for steroid hormone uptake in Drosophila. Dev Cell. 2018;47:294-305 e297.

68. Neuman SD, Bashirullah A. Reconsidering the passive diffusion model of steroid hormone cellular entry. Dev Cell. 2018;47:261-2.

69. Di YQ, Han XL, Kang XL, Wang D, Chen CH, Wang JX, et al. Autophagy triggers CTSD (cathepsin D) maturation and localization inside cells to promote apoptosis. Autophagy. 2020;1:1-23.

70. Riddiford LM, Cherbas P, Truman JW. Ecdysone receptors and their biological actions. Vitam Horm. 2001;60:1-73.

71. Gilbert LI. Halloween genes encode P450 enzymes that mediate steroid hormone biosynthesis in Drosophila melanogaster. Mol Cell Endocrinol. 2004; $215: 1-10$

72. Ono $\mathrm{H}$. Ecdysone differentially regulates metamorphic timing relative to 20hydroxyecdysone by antagonizing juvenile hormone in Drosophila melanogaster. Dev Biol. 2014:391:32-42.

73. Dinan L. Phytoecdysteroids: biological aspects. Phytochemistry. 2001;57:325-

74. Ajaha A, Bouayad N, Aarab A, Rharrabe K. Effect of 20-hydroxyecdysone, a phytoecdysteroid, on development, digestive, and detoxification enzyme activities of Tribolium castaneum (Coleoptera: Tenebrionidae). J Insect Sci. 2019;19:18.

75. Tu J, Jufri NF. Estrogen signaling through estrogen receptor beta and Gprotein-coupled estrogen receptor 1 in human cerebral vascular endothelial cells: implications for cerebral aneurysms. Biomed Res Int (2134). 2013;2013: 524324.

76. Deupi X, Kobilka BK. Energy landscapes as a tool to integrate GPCR structure, dynamics, and function. Physiology (6541). 2010;25:293-303.

77. Miao Y, McCammon JA. G-protein coupled receptors: advances in simulation and drug discovery. Curr Opin Struct Biol. 2016;41:83-9.

78. Rasmussen SG, DeVree BT, Zou Y, Kruse AC, Chung KY, Kobilka TS, et al. Crystal structure of the beta2 adrenergic receptor-Gs protein complex. Nature. 2011:477:549-55.

79. Katritch V, Cherezov V, Stevens RC. Diversity and modularity of G proteincoupled receptor structures. Trends Pharmacol Sci. 2012;33:17-27.

80. Sengupta D, Chattopadhyay A. Molecular dynamics simulations of GPCRcholesterol interaction: an emerging paradigm. Biochim Biophys Acta. 1848; 2015:1775-82

81. Periole X. Interplay of $\mathrm{G}$ protein-coupled receptors with the membrane: insights from supra-atomic coarse grain molecular dynamics simulations. Chem Rev (37369). 2017;117:156-85.

82. Farran B. An update on the physiological and therapeutic relevance of GPCR oligomers. Pharmacol Res (4816). 2017;117:303-27.

83. Yekkirala AS. Two to tango: GPCR oligomers and GPCR-TRP channel interactions in nociception. Life Sci. 2013;92:438-45.

84. Van Craenenbroeck K. GPCR oligomerization: contribution to receptor biogenesis. Subcell Biochem. 2012;63:43-65. 
85. Tian H, Furstenberg A, Huber T. Labeling and single-molecule methods to monitor G protein-coupled receptor dynamics. Chem Rev (37369). 2017;117; 186-245.

86. Thummel CS, Chory J. Steroid signaling in plants and insects--common themes, different pathways. Genes Dev. 2002;16:3113-29.

87. Gilbert LI, Rybczynski R, Warren JT. Control and biochemical nature of the ecdysteroidogenic pathway. Annu Rev Entomol. 2002;47:883-916.

88. Hunyadi A, Herke I, Lengyel K, Bathori M, Kele Z, Simon A, et al. Ecdysteroidcontaining food supplements from Cyanotis arachnoidea on the European market: evidence for spinach product counterfeiting. Sci Rep. 2016;6:37322.

89. Homem CCF, Steinmann V, Burkard TR, Jais A, Esterbauer H, Knoblich JA. Ecdysone and mediator change energy metabolism to terminate proliferation in Drosophila neural stem cells. Cell (2871). 2014;158:874-88.

90. Siehler S. Cell-based assays in GPCR drug discovery. Biotechnol J (3781). 2008:3:471-83

91. Sriram K, Insel PA. G protein-coupled receptors as targets for approved drugs: how many targets and how many drugs? Mol Pharmacol. 2018;93: 251-8.

92. Hauser AS, Attwood MM, Rask-Andersen M, Schioth HB, Gloriam DE. Trends in GPCR drug discovery: new agents, targets and indications. Nat Rev Drug Discov. 2017;16:829-42.

\section{Publisher's Note}

Springer Nature remains neutral with regard to jurisdictional claims in published maps and institutional affiliations.

Ready to submit your research? Choose BMC and benefit from:

- fast, convenient online submission

- thorough peer review by experienced researchers in your field

- rapid publication on acceptance

- support for research data, including large and complex data types

- gold Open Access which fosters wider collaboration and increased citations

- maximum visibility for your research: over $100 \mathrm{M}$ website views per year

At BMC, research is always in progress.

Learn more biomedcentral.com/submissions 